\section{Torsion of Testis}

SIR,-Many readers like myself will be grateful to Dr. B. Hanstead to be reminded in his letter (15 March, p. 715) of idiopathic scrotal oedema of children ${ }^{1}$ as a differential diagnosis of torsion of the testis. He quite rightly points out that "a few operations have been needlessly performed because of a mistaken diagnosis of torsion of the testis," and this in my view is as it should be. Mr. K. Mohay-ud-Din's letter (15 February, p. 445) pleads for early treatment of this condition, and his experience of having to remove a gangrenous testis is unfortunately not uncommon.

Epididymo-orchitis in the 10-16-year-old age group is a dangerous diagnosis made too frequently. Exploration of a subcutaneous organ is in my view mandatory if there is any possibility of there being, or having been, an early torsion of the testis ; firstly, because the most obvious physical signs develop rapidly only when it is too late to save the testis, and, secondly, because minimal physical signs at the time of examination may be due to a torsion spontaneously correcting itself only to recur later. A previous history of testicular pain or swelling was recorded in 20 of Barker and Raper's series of 38 patients with torsion of the testis. ${ }^{2}$

I have been responsible for two " needless operations" recently. One turned out to be torsion of the appendix of the epididymis and the other might possibly fit into the category of idiopathic scrotal oedema of children. It was a 14-year-old boy who had mild redness, tenderness, and oedema of the left side of the scrotum for 24 hours. A week previously he had bruised the left buttock in a fall, but this had resolved completely. I think the aetiology of the scrotal signs in retrospect may have been due to inguinal lymphangitis. Resolution occurred rapidly postoperatively with a course of penicillin.

Exploration of the testis at a stage when there is doubt in the diagnosis may of necessity prove at operation to be unnecessary sometimes, but it is the only way to save the majority of testes in cases of torsion when they are referred early enough. If torsion is confirmed I consider it good practice to fix the other side, preferably at the same time.-I am, etc.,

\section{Clatterbridge Hospital,}

W. B. Ashby.

\section{REFERENCES}

Hanstead, B., and John, H. T., British fournal of Urology, 1964, 36, 110.
Barker, K., and Raper, F. P., British fournal of
Urology, 1964, 36, 35.

\section{Tetracycline and Nystatin}

SIR,-On reading the correspondence in the B.M.F. on the subject (28 December, p. 186 , and 22 March, p. 781), there has been no mention of the article recently written by myself. ${ }^{2}$ The letter from Professor $H$. I. Winner (18 January, p. 186) is very reasonable but omits the following points.

Many patients on or after antibiotic therapy have Candida albicans in their stools without any apparent ill effect. Many patients with diarrhoea attributable to antibiotic therapy have Candida albicans in their stools, but the diarrhoea clears up without any antifungal therapy when the antibiotic is discontinued. In my work I only considered cases who had had post-antibiotic diarrhoea for longer than one month. These were attributed to gut hypersensitivity to Candida albicans in the same way as Aspergillus fumigatus causes hypersensitivity in the lungs of a few patients. Antifungal therapy (nystatin, Lactobacillus acidophilus, or indeed yoghurt) has helped these patients. According to my clinical colleagues (particularly the paediatricians) these cases are rare. Perianal itching and soreness due to post-antibiotic Candida albicans infection is rather more common and some patients know that they will get it every time they have an oral antibiotic unless antifungal therapy is given concurrently.

I do not believe that it is necessary to give nystatin with tetracycline as a routine. It is only needed when there is hypersensitivity of the perianal skin or the bowel to Candida albicans, or when there is a debilitating concurrent disease and systemic candidiasis is a danger.-I am, etc.,

Microbiology Laboratory,

\section{J. G. Alexander.}

ull Royal Infirmary,

\section{Hull, Yorks. REPERENCE}

Alexander, J. G., Current Medicine and Drugs,
1967, 8(4), 3.

\section{Otitis Externa}

SIR,-We see several cases of otitis externa each day in our practice, so your recent leading article (11 January, p. 70) on the subject was of interest.

It is true that pain is a feature of really severe oedematous otitis externa, but it is often caused by a coexisting otitis media. In the vast majority of cases of uncomplicated otitis externa the predominant symptom is that of itching, and if intense pain is present then the diagnosis of otitis media must also be considered. This is not always easy, as the tympanic membrane may be obscured by meatal oedema and debris. In otitis externa of this severity I prefer to use systemic antibiotic therapy in conjunction with local treatment because it is more effective than local treatment on its own, and because there may be coexisting otitis media.

I am in entire agreement with the use of wicks in the early stage of treatment of all but the most minor attacks, but do not believe it is correct to assume that local broadspectrum antibiotics and steroids are always necessary or desirable. The correct emphasis lies in carefully cleansing all debris from the meatus under direct vision and then ensuring correct drainage by means of a glycerin and ichthyol solution if cellulitis is severe, or gentian violet or hydrargaphen. If these measures fail then an appropriate antibiotic with or without steroid may help, but the risk of sensitization, the cost of these preparations, and the satisfactory results obtained in many cases with attention to basic principles does not make them always a first choice treatment.

There are many patients who suffer recurrent attacks of otitis externa throughout their tour in Singapore, especially after swimming. In this humid climate it is punishment indeed to forbid swimming, and in many cases such advice would be ignored. Many of them must also remain in a humid tropical climate for some time. I have found that a solution of benzoic acid $0.5 \%$, salicylic acid $0.5 \%$ in $30 \%$ alcohol, as recommended by Macbeth, ${ }^{1}$ is successful in preventing or reducing the frequency of attacks if it is instilled into the ear with a disposable syringe before and after swimming.-I am, etc.,

\section{Station Medical Centre, R.A.F. Seletar,
c/o G.P.O. Singapore. \\ REFERENCB \\ IAN H. MCKeE. \\ 1 Macbeth, R., Practitioner, 1967, 199, 735.}

\section{Spillage of Mercury in Aircraft}

SIR,-Doctors who travel by air may unwittingly be causing serious problems to aircraft maintenance engineers, due to spillage or leakage of mercury from sphygmomanometers carried as part of the "tools of trade." Mercury is regarded as a restricted article in air transport, and should not be carried either in hand baggage or in the normal luggage unless specially prepared and packed as freight.

The danger is, of course, serious corrosion of the alloys used in aircraft construction, and it is not difficult to imagine the problems that beset aircraft engineers using $x$-ray equipment trying to trace each globule in the vast holds of aircraft, or in a passenger compartment where hand baggage is inadvertently involved.

All doctors would be well advised to use the aneroid variety when travelling to avoid the necessity of special packing for the mercury type instruments, and they will certainly relieve aircraft engineers from many hours of unrewarding work, and reduce at least one possible cause of aircraft delays.I am, etc.,

J. Graham Taylor, Air Corporations Joint Medical Service. Heachrow Airport,

\section{Points from Letters}

\section{Fallacy in Morbidity Statistics}

Dr. W. G. Benson (Ramsgate, Kent) writes: I was horrified to discover recently that the diagnoses we insert on N.H.I. certificates are used for morbidity statistics. With such a large percentage of vague certification that there appears to be ("debility," "coryza," and even "inertia") the collection of these certificates is not only useless, but also 2 waste of time and money. ...

\section{Doctors from Overseas}

Dr. A. A. Khan (St. Clement's Hospital, London E.3) writes: . . . You must be labeuring under a false delusion when you think that medical immigrants enter Britain to earn more money (22 March, p. 729). This statement is based on sheer ignorance. . The world has changed. Now most of the doctors can easily earn more money in their own country than a consultant earns here, and in addition they enjoy more respect from their medical colleagues. They come to Britain in pursuit of learning because British patterns of education haunt their mind. The situation is changing now, as most overseas countries have their own postgraduate institutions. The standard of these places of learning not only equals the "hit and miss" royal colleges, but pertraps some of them are better. Doctors coming from overseas are well motivated. They are intelligent, and, despite the difficulties in their way, they adjust themselves, working in unpopular specialties in decaying hospitals, and they often achieve the highest qualifications which British medicine can offer. 